Portland State University

PDXScholar

1973

\title{
An Investigation of Handedness and its Relationship to the Site of Contact Ulcers
}

Colleen S. Colleary

Portland State University

Follow this and additional works at: https://pdxscholar.library.pdx.edu/open_access_etds

Part of the Speech and Hearing Science Commons, and the Speech Pathology and Audiology Commons

Let us know how access to this document benefits you.

\section{Recommended Citation}

Colleary, Colleen S., "An Investigation of Handedness and its Relationship to the Site of Contact Ulcers" (1973). Dissertations and Theses. Paper 2050.

https://doi.org/10.15760/etd.2049

This Thesis is brought to you for free and open access. It has been accepted for inclusion in Dissertations and Theses by an authorized administrator of PDXScholar. Please contact us if we can make this document more accessible: pdxscholar@pdx.edu. 
AN ABSTRACT OF THE THESIS OF Colleen S. Colleary for the Master of Science in Speech, with emphasis in Speech Pathology/Audiology presented June 1, 1973.

Title: An Investigation of Handedness And Its Relationship to the Site of Contact Ulcers.

APPROVED BY NEMBERS OF THE THESIS COMMITTEE:

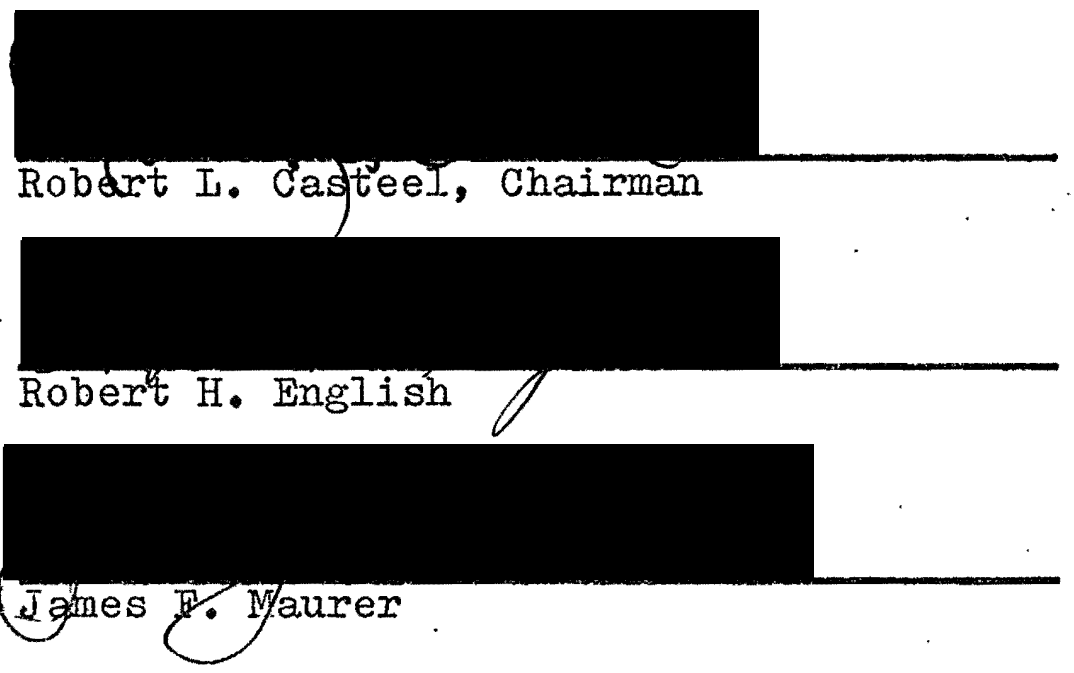

This investigation attempted to determine the relationship of the site of contact ulcers and subject's handedness. Iiterature concerned with contact ulcers has indicated that cerebral dominance tends to determine the site of the lesion. Four research questions were posed, two questions were presented in the form of the null hypothesis. The questions were: (1) Is the proportion of right-handed subjects with left-sided ulcers equal to 
the proportion of left-handed subjects with left-sided ulcers? (2) Is the proportion of right-handed subjects with right-sided ulcers equal to the proportion of lefthanded subjects with right-sided ulcers? (3) Will the site of contact ulcers be able to be predicted from subject's handedness? and (4) Is there a significant relationship between the factors of age, sex and occupation of the sample studied and the occurrence of contact ulcers? The research sample was composed of 21 former contact ulcer patients identified by their physicians. Eighteen subjects were male, three were female. Subjects ranged in age from twenty-one years to sixty-six years, with a mean age of forty-nine years. Subject's handedness was determined by means of a 15-item questionnaire constructed for this research study. Identification of the site of contact ulcers was made by medical records and physician designation. The Test of the Difference Between Two Proportions, the Phi Coefficient and percentages were used in processing the data. The major findings were as follows:

1. The proportion of right-handed subjects with left-sided ulcers is equal to the proportion of left-handed subjects with left-sided ulcers.

2. The proportion of right-handed subjects with right-sided ulcers is equal to the proportion of left-handed subjects with right-sided ulcers.

3. No statistical significance could be determined 
to support the hypothesis that the site of contact ulcers can be established from subject's handedness.

4. The majority of subjects sampled were middle-age males, employed in professional, technical or managerial positions.

On the basis of the sample of contact ulcer patients studied and the dimensions of location of the lesion and handedness involved in this investigation, the following conclusions appear to be warranted:

1. Handedness is not a determining factor in the site of contact ulcers.

2. It is not possible to predict the location of a contact ulcer based on knowledge of subject's handedness.

3. Contact ulcers occur more frequently in middleage males, whose occupations may be associated with vocal stress and strain. 
AN INVESTIGATION OF HANDEDNESS AND ITS REIATIONSHIP TO THE SITE OF CONTACT UICERS

by

COLLEEN S. COLLEARY

A thesis submitted in partial fulfillment of the requirements for the degree of

MASTER OF SCIENCE

in

SPEECH

With emphasis in Speech Pathology/Audiology

Portland State University 1973 
TO PHE OFFICE OF GRADUAPE STUDIES AND RESEARCH:

The members of the Committee approve the thesis of . Colleen S. Colleary presented June 1, 1973.

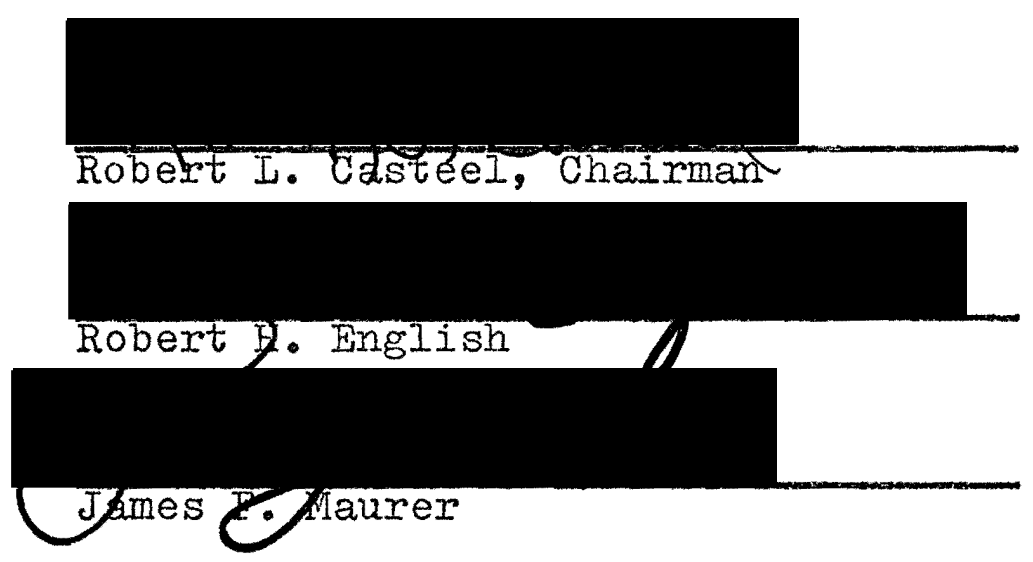

\section{APPROVED:}

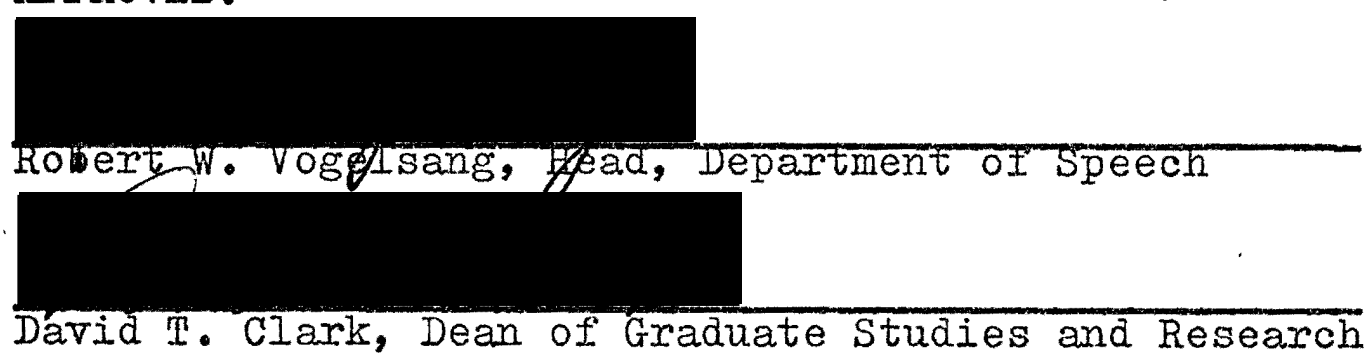

June 29,1973 


\section{ACKNOWJEDGMENTS}

I wish to express sincere appreciation to:

Dr. Robert I. Casteel for his capable direction, indispensable assistance, continued support and encouragement throughout this investigation.

Drs. Robert H. English and James F. Maurer for their helpfui comments and suggestions throughout the study.

Mrs. Ethel Lawrence for providing statistical advice and consultation.

Dr. David D. DeWeese, Chairman Dept. of Otolaryngology, University of Oregon Medical School, and Mr. Caxl Anderson, Portland Clinic, for their generous and dependable help on many occasions during the course of this study.

The Research and Publications Committee, Portland State University, for providing funds for this research. The subjects who participated in this investigation and made this research study possible. 
TABLE OF CONTENTS

PAGE

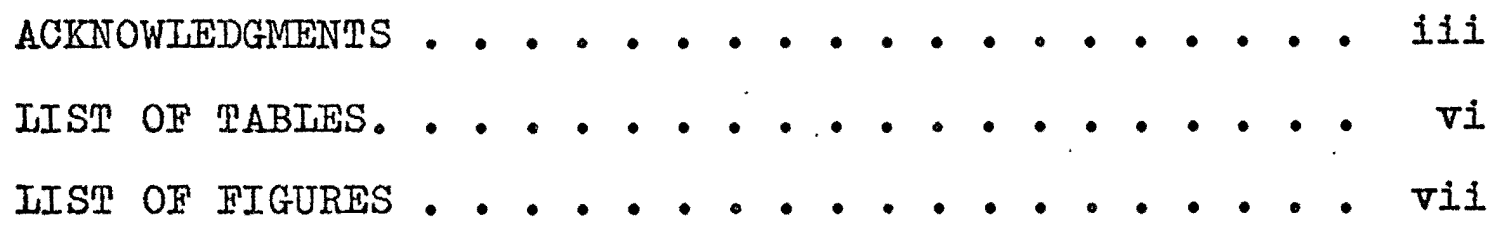
CHAPTER

I INTRODUCTION AND STATENENT OF THE PROBLEM • 1

I. INTRODUCTION. . . . . . . . 1

II. STATEMENT OF THE PROBLEM. . . . . 5

Definition of Terms

II BACKGROUND OF THE PROBIEM • • • • • • . 9

I. CONTACT ULCER •. . . . . . . 9

Etiology
Identification
Related Factors
Symptomatology
Pathology

II. IATERALITY, DEXTRALITY AND SINISTRAIITY . . . . . . . 18

The Issue

Definition and Classification

Form of Preferred Laterality

Complete Dominance

Preferred Laterality As A Patterm

Test Items Selected

III SUBJECTS, METHODS AND PROCEDURES. . . . 26

I. SUBJECTS. . . . . . . 26 
II. METHODS. . . . . . . . . . 26

Construction of the Questionnaire

Scoring Procedures

III. PROCEDURES . . . . . . . . 28

Experimental Sample

Control Group

Data Analysis

IV RESUITS. . . . . . . . . . . . 30

I. GENERAI. . . . . . . . 30

Comparative Analysis

Identification of the site of

Ulcer

II. SPECIFIC HYPOTHESES. •. . . . 40

$\mathrm{V}$ DISCUSSION . . . . . . . 42

VI SUMMARY AND IMPIICATIONS . . . . . . 48

I. SUMmaRY. . . . . . . 48

II. IMPLICATIONS FOR FUTURE RESEARCH • . 50

BIBLIOGRAPHY . . . . . . . . . 52

APPENDIX

A FORM IEETER SENT TO PHYSICIANS . • • • 55

B STAMPED, SELF-ADDRESSED POST CARD SENT TO PHYSICIANS . . . . . . . 58

C QUESTIONNAIRE ON SUBJECT'S OCCUPATION, SEX AND HANDEDNESS . . . . . . . . . 60

D INTRODUCTORY IETTER SENT TO PATIENTS . . . 63

E IIST OF SUBJECT'S OCCUPATIONS. . . . . . 65 


\section{IIST OF TABIES}

TABLE

PAGE

I Classification of Subject's Occupations . . 31

II Comparison of DQ Scores for Research Sample and Pilot study . . . . . . . 33

III Site of Contact Ulcer and Determined Handedness for Research Sample. . . . . 38

IV Site of Contact Ulcer and Determined Handedness for Peacher Research Sample. . . 


\section{IIST OF FIGURES}

1. Illustrations of Normal Vocal Process,

One Sided Contact Ulcer, and

Bilateral Contact Ulcers . . . . .

2. Frequency of Occurrence and Distribution

of $D Q$ Scores for Research Subjects

Based on 15-Item Test. . . . . .

3. Frequency of Occurrence and Distribution

of $\mathrm{DQ}$ Scores for Research Subjects

Based on 8-Item Test . . . . . 36

4. Frequency of Occurrence and Distribution

of $\mathrm{DQ}$ Scores for Pilot Subjects

Based on 15-Item Test. . . . . . 36

5. Frequency of Occurrence and Distribution

of $D Q$ Scores for Pilot Subjects

Based on 8-Item Test . . . . . . 37 


\section{CHAPTER I}

\section{INTRODUCTION AND STATEMENT OF THE PROBLEM}

\section{INTRODUCPION}

From the time Chevaliex Jackson (1928), first distinguished the uncommon contact ulcer from other laryngeal pathologies, this voice disorder has been a controversial topic of research. The study of the infrequently occurring contact ulcer lesion has included its correlation with such factors as age, sex, occupation, vocal infections, tobacco and alcohol. Primarily, strong relationships have been established with age, sex and occupation. of particular interest have been the studies concerming the site of the lesion on the vocal process and the possible relationship of the ulcer to cerebral dominance.

In discussing the site of the lesion, whether it be on the right or left vocal process, Holinger and Johnston (1960) found that in the 92 cases they reviewed 26 possessed the ulcer or granuloma on the right vocal process, in 35 cases the ulcer appeared on the left vocal process and 31 cases had bilateral lesions. The Peacher study of 1961 would appear to be the first to hypothesize that cerebral dominance was related to the site of the ulcer on the 
involved vocal process. She reported that right and lefthandedness was related to the site of the ulcer on the right or left vocal process. In her study she found the ulcer on the non-dominant vocal process in 83 percent of her subjects. A breakdown of her percentages are as fol-

\section{lows:}

81 percent xight handed

12 percent right handed

2 percent left handed

5 pexcent left handed ulcer on the left cord ulcer on the right cord ulcer on the right cord ulcer on the left cord

In the five cases studied by Wolcott (1956), he reports that in all cases which were right-handed the left arytenoid area revealed more pathology, while the one lefthanded subject possessed the ulcer on the right process. Wolcott concludes,

- . that this seems to suggest that under stress, in the right-handed person, the right cord becomes what Jackson termed the hammer and inflicts trauma to the left cord or anvil. In the left-handed individuals the opposite condition occurs. If the action is prolonged the hammer may become involved.

Armold (Iuchsinger and Armold, 1967), has long suspected that the site of the ulcer may be related to cerebral dominance. He states ". . that the active granuloma of contact ulcers seems to occur more frequently on the dominant side, while the passive ulcer is then on the minor side." This conclusion appears to be in direct opposition to Peacher's (1961) hypothesis of cerebral dominance and site of the lesion. Applying Jackson's hammer and anvil effect, Amold would appear to be saying that if the contact ulcer 
patient is right-handed, the active granuloma would appear on the right vocal process since the left vocal process (being the hammer) inflicts trauma to the right vocal process (being the anvil). If this is indeed Arnold's hypothesis it appears that he has not substantiated a cerebral dominance theory and his view is then in direct opposition to Peacher's (1961) hypothesis. Yet, Armold cites Peacher's 1961 study as confirmation of the fact that localization of contact ulcers does indeed depend on handedness.

Armold (1962), however, criticizes Peacher's lack of information with regard to the manner used to establish cerebral dominance. He suggests it is possible that refined testing of true innate handedness, with due classification of crossed, shifted, pathological or ambilateral dominance, might reveal an even higher correlation between localization of contact ulcers and handedness.

The confusion of the preceding literature definitely demonstrates the need for clarification and definition of terminology concerning cerebral dominance, handedness and Jackson's hammer and anvil effect. In particular, several discrepancies noted in the Peacher (1961) study require clarification. The discrepancies are as follows: the size of the sample studied is not specifically stated; (2) the method of determining handedness is not presented; (3) sex incidence is not noted; and (4) Peacher's cerebral 
dominance theory is not supported in the left-handed population where 5 percent possessed the ulcer on the left side and 2 percent possessed the ulcer on the right side.

In view of the conflicting reports of authors (Peacher, 1961; Arnold, 1962) concerning the dominance theory and the site of contact ulcers, acceptance of this theory would appear to be questionable. Given, however, the hypothesis that regardless of handedness the localizam tion of the contact ulcer lesion will appear predominantly on the left vocal process, the Peacher (1961) and Holinger and Johnston (1960) studies would appear to substantiate this theory.

As previously reported, Holinger and Johnston (1960) in their study of 92 cases found that 35 patients ( 38 percent) possessed the lesion on the left vocal process as opposed to 26 patients (28 percent) who possessed the lesion on the right vocal process and 31 patients ( 34 percent) who had bilateral lesions. Peacher's (1961) data reveal that 86 percent of her subjects possessed the ulcer on the left vocal process. In the case of bilateral contact ulcers, Peacher reports the larger ulcer was designated.

Although, the Peacher (1961) and Holinger and Johnston (1960) studies appear to support the theory that the left vocal process is most frequently involved in the occurrence of a contact ulcer, Brodnitz (1961) 
refutes this theory stating that reports of a larger series of studies do not confirm this assumption. Brodnitz, however, does not cite the series of reports to substantiate his claim.

The hypothesis that handedness is a determining factor in the site of contact ulcers would not appear to be substantiated by the Peacher (1961) data, due to the lack of specificity to afford or affirm such a hypothesis. Furthermore, Brodnitz (1961) through the analysis of a larger series, challenges the supposition that the left vocal process appears to be more frequently involved in the occurrence of contact ulcers.

To this investigator there remains doubt concerning the relationship between handedness and the site of the contact ulcer lesion, therefore, further investigation appears to be warranted.

\section{STATEMENT OF THE PROBLEM}

Primarily, this study will be concerned with the relationship of the site of contact ulcers and subject's handedness. Secondarily, research data will be examined to determine possible relationships between the factors of age, sex and occupation of the sample studied and the occurrence of contact ulcers.

This study will endeavor to answer the following questions: 
1. Is the proportion of right-handed subjects with left-sided ulcers equal to the proportion of left-handed subjects with left-sided ulcers?*

2. Is the proportion of right-handed subjects with right-sided ulcers equal to the proportion of left-handed subjects with right-sided ulcexs?*

3. Will the site of a contact ulcer be able to be predicted from the subject's handedness?

4. Is there a significant relationship between the factors of age, sex and occupation of the sample population studied and the occurrence of contact ulcers?

Two research hypotheses to be tested by this study are presented in the form of the null hypothesis.

Hypothesis (I): The proportion of right-handed subjects with left-sided ulcers is equal to the proportion of left-handed subjects with left-sided ulcers.

Hypothesis (II): The proportion of right-handed subjects with right-sided ulcers is equal to the proportion of left-handed subjects with right-sided ulcers.

*In the case of bilateral contact ulcers, the vocal process possessing the larger lesion will be designated as the site of occurrence. 
Definition of Terms

To facilitate the understanding of this paper, a few definitions basic to the subject under investigation are presented here. Other definitions, more specific to subparts of this paper, will appear in context.

Contact Ulcer. The superficial ulceration occurring on one or both sides of the larynx posteriorly, the ulcerated surface coming in contact with that of its fellow on the opposite side, the latter being ulcerated or not, according to whether the ulcer is monolateral or bilateral (Jackson, 1928). A benign tumor which originates posteriorly on the medial surface of the voeal process of the arytenoid cartilage or on the ascending approximating surfaces up to the apex of the arytenoids (Holinger and Johnston, 1960).

Handedness. A tendency to use one hand rather than the other (Webster, 1965).

Hand Usage. An expressed or demonstrated preference for using one hand rather than the other (Johnson and Duke, 1936).

Cerebral Dominance. One side of the brain appears to take precedence over the other in the neural organization of behavior (Buck, 1968). Thus the dominant hemisphere is contralateral to the preferred hand (Jackson, 1928).

Middle Age. Traditionally extends from age forty to sixty in the life span (Hurlock, 1959). 
Ambi. Prefix: both or both sides; around; about (Taber, 1970).

Ambidextrous. [Dexter, right] ability to work effectively with either hand (Taber, 1970).

Ambilateral. Pertaining to or affecting both the right and left side (Dorland, 1965).

Ambilevous. Awkward in use of either hand (Taber, 1970).

Dexter. Right; in official anatomical nomenclature, used to designate the right hand one of two similar structures, or the one situated on the right side of the body (Dorland, 1965).

Dextral. (1) Right as opposed to left, (2) a righthanded person (Dorland, 1965).

Dextrality. The preferential use, in voluntary motor acts, of the right member of the major paired organs of the body, as the right eye, hand or foot (Dorland, 1965).

Sinistral. (1) Pertaining to or showing preference for the left hand, eye, or foot in certain actions, on the left side (Taber, 1970).

Sinistrality. Ieft-handedness (Taber, 1970). 
CHAPTER II

BACKGROUND OF THE PROBLEIM

I. CONTACT ULCER

Jackson (1928) published his first paper on contact ulcers in which he presented typical signs and symptoms. He presented the following definition of this clinical entity:

Contact ulcer is the name I have given to superficial ulceration occurring on one or both sides of. the larynx posteriorly, the ulcerated surface coming in contact with that of its fellow on the opposite side, the latter being ulcerated or not, according to whether the ulcer is monolateral or bilateral.

Jackson claimed that these lesions, heretofore, were frequently overlooked altogether in the milder cases or mistaken for tuberculosis or malignant disease in the case of larger lesions. He stated that superficial erosions were not uncommon in chronic laryngitis, but the unique ulcerative lesion, contact ulcer, deserved a special designation and a particular recognition (Peacher, 1947).

Theories regarding causation of the contact ulcer range from mechanical causes to physiologic aberrations, allergies, hormonal or autonomic imbalance, and even psychosomatic influences ( $v$ on Leden and Moore, 1960). More specifically, many factors such as chronic upper 
respiratory infection, excessive use of tobacco and alcoholic beverages, irritative industrial environments and rocal abuse have been considered as having etiological relations (Wolcott, 1956).

\section{Etiology}

Jackson was the first to draw attention to the hammer and anvil actions of the vocal processes as they hit together during forceful phonation or violent clearing of the throat. He hypothesized, that since the mucous membrane overlying the cartilaginous vocal processes is very thin, mechanical traumatization would appear to be an important factor in producing the contact ulcer (Iuchsinger and Amold, 1967).

On the basis of extensive clinical, cinematographic and experimental observation, von Leden and Moore (1960) concluded that the origin of a contact ulcer is based on several different factors, all of which contribute to its development. They stated:

\footnotetext{
- while the anatomical configuration of the involved structures undoubtedly predisposes to injury we believe that the principal causative factors are based on physiologic circumstances, as they relate to the function of the vocal folds.
}

They produced films on contact ulcers which showed the formation of the ulcer after repeated production of very harsh glottal strokes. They describe the ulcer as a hyperfunctional or hyperkinetic disorder. Their film 
demonstrates a rotation in the cricoarytenoid joint in two planes during the glottal stroke. They found that during the production of a deep, throaty voice, often found in contact ulcer patients, there was a wider excursion of this rocking kind of motion and a more prolonged approximation of the arytenoids, exposing the inner surfaces around the vocal processes to greater stress. At low pitch, the arytenoid approximation persisted beyond the period of vibratory motion, and each change in pitch changed the angulation of the arytenoids, exposing the contacting surfaces to scraping injuries. At medium or higher pitch the arytenoid cartilages showed greater stability.

Von Leden and Moore also observed that loudness increased both the vigor and duration of arytenoidal approximation during each vibratory cycle. The rocking or grinding motion while approximated was particularly noted during harsh, gutteral sounds. Von Leden and Moore (1960) conclude that their film would appear to demonstrate the factors responsible for the occurrence of the contact ulcer around the vocal processes.

Some authors (Iuchsinger and Arnold, 1967) believe emotional factors play a major role in the etiology of the contact ulcer. Moses (1959) observed the sudden development of a contact ulcer under severe emotional stress. Brodnitz (1961) concurs with this opinion, stating 
that "emotional pressures exert a conditioning influence on voeal behavior and condition the larynx indirectly to the pattern of enforced voice production that produces the ulcer." Rubenstein (1951) reports the case of a patient with recurrent ulcers and gxanulations which disappeared spontaneously after severe emotional difficulties were resolved. Ferguson (1955) states that ". . the patient with contact lesions usually exhibits the maximum of nervous tension, often coupled with a past history of 'nervous breakdown" or other psychiatric problems." He describes the patient as an ". . over-doer, mentally, physically and verbally."

According to Brodnitz (1961), the autonomic nervous system seems to play a major part in predisposing a person to contact ulcer. In Armold's (1962) opinion, contact ulcer of the larynx may be compared to intestinal ulcers. He states that:

\footnotetext{
- - in both cases, there is evidence of localized vasoconstriction, that is, blanching of the muscosa, which reduces local resistance. It is well knowm that vasospasms are associated with states of emotional tension. On the basis of such local predisposition, some additional mechanical, chemical or inflammatory factor may act as a precipitating cause, bringing about the acute onset of the ulcer. Similar to migraine headache, laryngeal contact ulcer seems to occur frequently in individuals with a perfectionistic personality who are compulsively hard workers, make great demands on themselves, and tend to build up inner tensions without relaxation or exteriorized discharge. In psychoanalytic parlance, one might say that such a person 'swallows' their tensions and problems until they 'choke' from their unresolved conflicts.
} 
Besides describing contact ulcer with regard to its non-specific origin, as noted in the preceding literature, some authors use the term to describe specific origin. Specific causes as described by Baker (1957) are pulmonary tuberculosis, endotracheael anesthesia, and carcinoma. The term contact ulcer, however, is usually reserved to specify a chronic non-specific inflammation caused by trauma (Holinger and Johnston, 1960).

\section{Identification}

The presence of a non-specific contact ulcer of the larynx may be established by means of mirror laryngoscopy. Typical lesions at the tip of one or both vocal processes are easily seen. Jlceration with or without granuloma may be present (New and Devine, 1949). The ulcer may be a polipoid mass or new granulation tissue or a small, hard fibrous nodule composed of inflammatory fibrous tissue. Unlike rocal nodules, contact ulcers are indentations rather than projections, but granulation accumulating in the depression may in time build up and hinder the closure of the posterior ends of the folds (New and Devine, 1949).

\section{Related Factors}

In studying the laryngeal pathology, known as contact ulcer, several authors frequently cite factors that appear to be related to the occurrence of this lesion. For the purposes of this study the following factors will be 
discussed:

Sex. Contact ulcer is primarily a pathology of the male (Brodnitz, 1962). Peacher (1947) estimates the relationship between male and female patients at 15:1. Jackson (1933) saw only 8 women in 106 cases while New and Devine (1949) saw no women in a series of 44 cases; only 8 of 92 patients reported by Holinger and Johnston (1960) were women; and Brodnitz (1962) found no women in 26 cases. Age. Contact ulcer is a disease of middle age (Brodnitz, 1962). Peacher (1947) reported patients between 27 and 69 years of age with an average of 50. Holinger and Johnston's (1960) patients ranged in age from 28 to 72 years with no average age cited. Brodnitz's (1960) patients were between 31 and 70 years old with an average age of 48 . Occupation. Holinger and Johnston's (1960) study of 92 patients states that the occupation(s) of the male patients ". . are recognized as being associated with rocal stress and strain." Their study sample consisted of 21 salesmen, 11 preachers or teachers, 10 physicians, 9 managers of business, 6 lawyers and 12 subjects who were factory or railroad workers whose jobs required shouting or talking over a loud noise. Jackson (1933) and Peacher (1947) contend that occupation has a bearing on the etiology of contact ulcer especially in connection with the amount of use of voice required by the particular occupation. Both Moses (1954) and Brodnitz (1958) write that contact ulcers 
are frequently found in the hard-driving type of man who is under a great deal of daily tension (Boone, 1967). The literature previously reviewed would apparently substantiate the belief that the contact ulcer lesion occurs, though infrequently, most commonly among a predominantly middle-age male population, who demonstrate vocal hyperfunction and whose occupation may be associated with vocal stress and strain.

Symptomatology

Hoarseness appears to be a frequent symptom of contact ulcer (Peacher, 1947). The degree to which the voice is impaired varies from an extremely slight huskiness to an intense hoarse quality, depending upon the amount of granulation tissue or ulceration present (DeWeese, 1964). Hoarseness is often times accompanied by a constant desixe to clear the throat (Peacher, 1947). Pain is sometimes an accompanying symptom of contact ulcer and may radiate to one or both ears (Brodnitz, 1962), oftentimes being aggravated by talking and swallowing (Peacher, 1947). The pain is manifested usually as a slight stinging or tickling sensation. Infrequently, it assumes a sharp and stablike character. The voice may tire easily (Boone, 1971) and the patient may experience the sensation of foreign bodies in the throat and the necessity to clear the throat often. Patients report that the hoarseness increases after con- 
tinued rocal usage and at this time a tired or aching feeling is apparent in the throat. Coughing is usually present (Peacher, 1947), though Jackson (1942) believes that this reflex is not excited by the ulcer per se. According to Van Riper and Irwin (1958) the effect of these ulcers upon the voice is quite similar to that produced by rocal nodules. The patient speaks with a low pitched voice, employing a hard glottal attack (Boone, 1971) which sounds deep, throaty and harsh (Brodnitz, 1959), and frequently possesses the quality disorder of hoarseness. Aphonia occurs only raxely (Van Riper and Irwin, 1958). Characteristically the voice becomes worse as (1) the pitch is lowered, and (2) increased intensity often brings on soreness or tickling and more hoarseness. Some air wastage often occurs prior to phonation (Van Riper and Irwin, 1958).

Pathology

A contact ulcer originates on approximating cartilaginous surfaces of the arytenoid cartilages as a superficial, soft, shallow ulcer (Holinger and Johnston, 1960). As the process continues, an increased vascularity is evidence of the inflammation characteristic of this clinical entity. A granuloma may develop which is covered with white exudate to give the most typical appearance of a contact ulcer (See Figure 1). Often the white mass is 


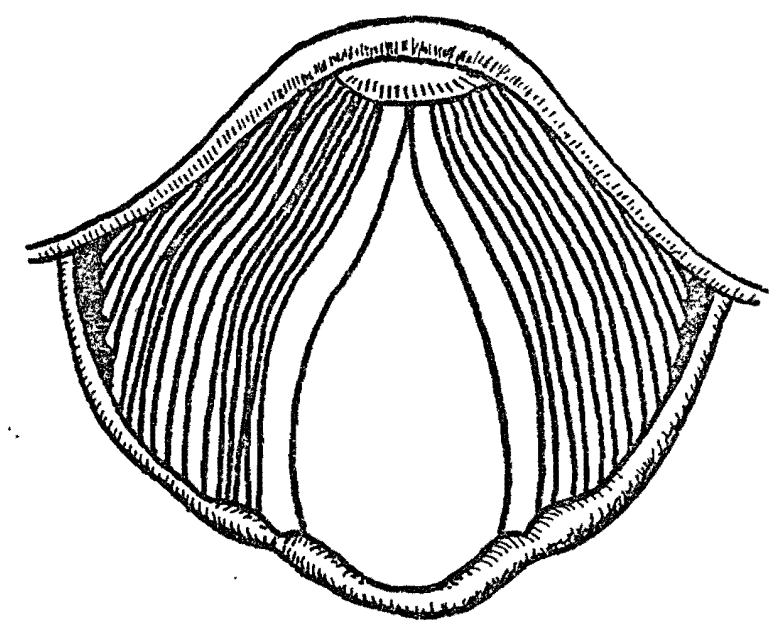

a.
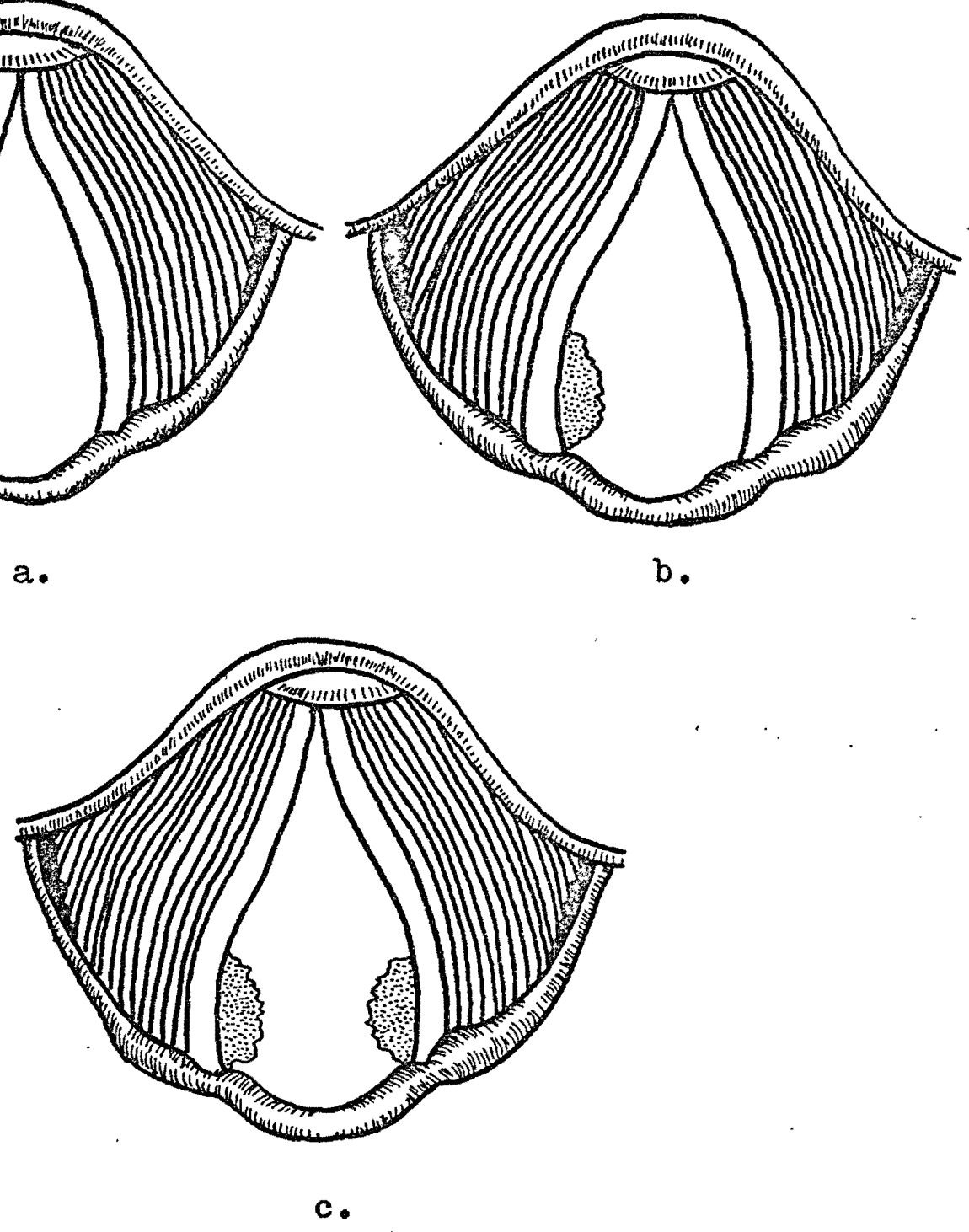

Figure 1. Superior view of the larynx.

a. Normal larynx viewed during inhalation (white bands indicate true folds).

b. Larynx with stippling indicates location of contact ulcer on one-fold.

c. Iarynx with bilateral contact ulcers. 
surrounded by a fine, bright red inflammatory zone, and in some cases the necrotic ulcer becomes surrounded by a large pad of granulation tissue. In more chronic, longstanding lesions, the granuloma becomes organized, smooth and discrete. Occasionally, it becomes extremely large, sliding under the opposite cord during phonation or fitting directly into a deep cratex on the opposite arytenoid cartilage (Holinger and Johnston, 1960). In essence, the lesion is a granulation tissue reaction to chronic irritation and inflammation (Holinger and Johnston, 1960).

\section{IATERAIITY, DEXTRAIITY AND SINISTRAIITY}

Iaterality, sidedness, would seem to be a relatively obvious determination in adults; however, there clearly has been much confusion in the literature and a dearth of reliable criteria and data.

Blau (1946) has stated that:

- . ever since man became conscious of his two hands as instruments for doing a multitude of things, and began to notice the greater efficiency of one particular hand, the question of preferred laterality, or sidedness, has intrigued him. Animals, infants, children and adults have been the subjects of intensive observation, and experiments have been deliberately conducted for generations to change the handedness of children. All of this has resulted in an accumulation of theories, some so bizarre and fantastic that one finds it hard to believe the seriousness of their authors. Other theories are based on apparently sound observations, yet are so varied and contradictory that they becloud the question. It is therefore not surprising that, despite all the writing and research, the phenomenon is still shrouded in mystery. 


\section{The Issue}

The phenomenon of one-sided preference is recognized as involving not only the hands but the eyes, legs and other paired functions which manifest a tendency toward right or left preference. The term used in general to designate this trait of "sidedness" or "dominance" is "laterality," with "dextrality (right)" and "sinistrality (left)" being employed to establish the particular localization of preference (Blau, 1946). The more specific aspects of the phenomenon have been referred to as the "master hand," "dominant leg," "eyedness" and so on, designating right or left as the case may be (Blau, 1946).

Definition and Classification

By the term preferred laterality (or preference, dominance, sidedness, master side) reference is made to the human tendency to use one side in preference to the other for certain one-sided skilled acts (Blau, 1946). According to Blau (1946), "another feature is that the idea of a "master" organ or activity, involves the quality of activity in contrast to passivity." Blau continues by saying that most performances require the cooperation of both sides. In such cases, the preferred hand takes the master role while the other assists in the performance. When viewed from the standpoint of the act as a whole, it appears that the supporting contribution is no less 
significant. The designation, preferred laterality, according to Blau (1946), therefore merely accents the side which has active precedence and in that respect is apparently the superior one. In more bimanual activities, Blau (1946) contends that "it is more difficult to decide which is the master hand." He continues by saying that it has been suggested that in bimanual activities the master hand takes on more of the work.

\section{Form of Preferred Laterality}

The most widely recognized form of preferred laterality involves the hands, that is handedness. In discussing the incidence of hand preference a review of the literature shows a great deal of variety in the figures reported by different investigators. Wile (1934) tabulated the findings of 26 authors and found from one to thirty percent sinistrality. In another review, Selzer (1933) showed a range of two percent to twenty-eight point seventynine percent for left-handedness. Blau (1946), believes that the wide variance in the estimates does not necessarily reflect personal degrees of conservatism or individual inaccuracies, but can perhaps be accounted for by differences in testing methods and the groups tested. He feels "it thus becomes clear that in comparing one study with another, we must compare not only the resulting figures but also the other factors, especially the standards of 
testing." According to Blau (1946), "in the final analysis, it seems that the most reliable estimate of (sinistrality) - . is the conservative approximation of 2 to 6 percent."

Complete Dominance

The notion that a person is either completely right or left in his choice of laterality has been quite prevalent. A right-handed person is thus presumed to be such in all manual activities.

While it is true that right and left are complimentary opposites, there is no sound reason why differentiation for various manual activities in one individual must all fall on one side. In some activities the right may be more efficient, in others the left, but the right-handed tendency need not always manifest itself as a complete trait.

The problem of the definition of manual preference has been well presented by such authors as Johnson and Duke (1936, 1940), Johnson and Davis (1937), Johnson and Bissell (1940), Blau (1946), Benton (1961), and Hecaen and Ajuriaguerra (1964). These investigators essentially showed the need for quantitative evaluation of the dexterity of the preferred hand, and the qualitative analysis of the results, before establishing the real nature of the manual preference (Hecaen and Ajuriaguerra, 1964). In the view of some authors, we can do no more than describe a certain patterm of right or left-handedness for a given 
individual, for given activities, and at a given period of his life (Hecaen and Ajuriaguerra, 1964).

Despite these apparent variations and inconsistencies in manual preference, the distribution of laterality is not irregular or chaotic, but shows a definite trend and pattern favoring the right as the master side. As Blau (1946) states:

- . this right dominance is especially prevalent in certain activities. The keynote is not in the native inherent predisposition but in the complexity of the activity involved.

Blau (1946) in studying the laterality pattern of an unselected group of 532 high school boys, 12 to 20 years of age, utilizing six tests of laterality, noted that the more specialized and differentiated the activity, the higher the degree of right-sided development, while the simpler ones approached a 50-50 chance division. Blau (1946) stated that:
- . the apparent increase of right-sided prefer- ence in proportion to the complexity or the nature of an activity acquired by learning, suggests that training and education are the essential factors in the development. of right preference. It would seem that the individual is influenced more by the right- sidedness of the world he lives in than by any hypo- thetical, intrinsic element.

Corballis and Beale (1971) in discussing right-left discrimination appear to substantiate Blau's statement, when they conclude that in general it appears that left-right asymmetries are particularly associated with the kinds of behavior that are no longer restricted to the natural 
environment. They believe that the large majority of leftright asymmetries exist only in the man-made environment.

\section{Preferred Laterality As A Patterm}

In light of the comprehensive view of the laterality phenomenon, the determination of a preferred dextrality or sinistrality is seen as a complicated project. There may be difference of laterality between various activities of one organ or function and among different organs or functions in the same individual. The over-all situation therefore seems to indicate that laterality and more specifically handedness, cannot be determined definitely by any one test. All one can truly aim at is to establish a pattern of handedness for a particular person in light of activities tested (Blau, 1946). In order to do so, a qualitative description of the pattern, such as a dextrality quotient or handedness formula would appear to be a valuable testing tool.

Employing a Dextrality Quotient in handedness studies, Johnson and Duke (1936, 1940), Johnson and Davis (1937) and Johnson and Bissell (1942) discovered an interesting finding involving the nature of the distribution of data they obtained. The afore mentioned researchers found that the distribution of Dextrality Quotients shows an essentially single mode curve skewed toward the right-handed side of the distribution. Results of the preceding studies would 
appear to refute the commonly held assumption that handedness is distributed in a distinctly bimodal fashion.

It is also of interest to note that a comparison of the 1936 and 1940 Dextrality Quotient studies, based on a six year old research population, and the 1937 DQ study, involving seven year olds, demonstrates a tendency for the entire distribution of scores to shift toward the right-hand end of the scale as a function of age. The 1942 study involving high school students essentially shows this tendeney. The data would then appear to suggest that the subjects become more right-handed in terms of hand usage as they become older, thus supporting Orton's (1937) statement:

tendency to develop the predominant use of either
the right or the left hemisphere ${ }^{-}$. handedness,
however, is so freely open to the influence of
training that the resultant patterns which one
finds are a combination of the hereditary bent
and the effects of training.

Test Items Selected

The best type of test for establishing a pattern of handedness would appear to be one that sampled skilled manual activities. The skilled acts determine the present form and extent of the subject's lateral differentiations in his useful and skilled activities (Blau, 1946). Testing these skills it would appear that the examination reveals how the individual up to the time of the test, has responded 
to the moxe accepted right-handed orientation of the world about him, and how much difference and apparent conflict there is in his laterality make-up (Blau, 1946). 


\section{CHAPTER III}

SUBJECTS, METHODS AND PROCEDURES

\section{SUBJECTS}

The population upon which this investigation was based consisted of a total sample of twenty-seven contact ulcer patients residing primarily in the state of Oregon, with one subject from the states of Washington, Califormia, and Iouisiana, who were identified from medical records by Oregon area 0tolaxyngologists.

\section{METHODS}

Sixty-one Otolaryngologists residing in Oregon were queried by form letter (See Appendix A) to indicate whether or not they had formex contact ulcer patients available for participation in this study. A stamped, self-addressed post card was included for response information (See Appendix B).

Replies were received from 11 physicians, 6 of whom indicated they had subjects for this study. The 6 participating physicians were interviewed either by telephone and/or personal visitation and requested to supply the following information: name, address, age, sex and site of the patients' lesion, whether it occurred on the right, 
left or bilaterally. The information was to be mailed to Portland State University, Department of Speech.

Constmuction of the Questionnaire

It was necessary to construct a questionnaire to test the hypothesis that the site of contact ulcers is related to subject's handedness.

The questionnaire involved two sections (See Appendix c). Section one contained four open-formed questions and three closed-formed questions dealing with the subject's occupation, sex and change of handedness (if applicable). Section two contained fifteen closed-form questions concerming the assessment of the subject's handedness in specifically defined tasks. Eight of the closed-form questions were adapted from the Iowa Hand Usage rest (Johnson and Duke, 1936, 1940). Specifically, these questions were numbers: $1,2,3,4,5,10$, and 11. Two questions were adapted from the Harris Tests of Lateral Dominance, they were numbers: 13 and 14 . The remaining five closed-form questions were constructed specifically for this study.

Scoring Procedures

For purposes of analysis, measurement of handedness was scored in terms of a Dextrality Quotient (DQ), as described by Johnson and Duke (1936, 1940), Johnson and Davis (1937), and Johnson and Bissell (1942). The DQ 
being defined as the percentage of the total achievement involved in any test of handedness which is to be credited to the right hand. The Dextrality Quotient was computed for each subject by means of the formula $D Q=\frac{R+.5 B}{N}$ in which $R$ and $B$ represent the number of operations performed by the right hand and by both hands (neither hand predominating), respectively, and $N$ represents the total number of operations performed.

Selection of the Dextrality Quotient for scoring purposes was based on the consideration that the DQ may be used as a universal scoring unit for tests of handedness. As such, it makes possible a significant reduction of the chaos involved in the present heterogenity of scoring units and scoring systems applied to measures of handedness (Johnson and Duke, 1936). By employing the DQ, the possibility of correlating one handedness test with another and establishing significant handedness test norms is greatly heightened.

\section{PROCEDURES}

Experimental Sample

Twenty-seven questionnaires, an introductory letter (See Appendix D) and a stamped, self-addressed response envelope were mailed to patients with a history of contact ulcers as identified by their physicians. 
Control Group

A pilot study was conducted primarily to determine the reliability of test items selected for the research questionnaire and more specifically, to check the reliability of test items adapted from the Iowa Hand Usage Test. Secondarily, the pilot study was conducted to provide information concerning individual variations of left and right handedness with the current fifteen-item test. In order to select a control group, a random order number table was used to select a matching number of adult graduate students in Speech Pathology and Audiology attending Portland State University. Questionnaires were distributed to the subjects and returned to the speech department.

\section{Data Analysis}

To determine the relationship of test items selected for the research questionnaire and those items adapted from the Iowa Hand Usage Test, the Spearman Correlation Coefficient will be computed. The significance of data concerning the factor of age will be reported. Additionally, the significance of data involving factors of sex and occupation will be established by means of percentages. The Test of the Difference Between Two Proportions and Phi Coefficient will be computed to establish the significance of the relationship of handedness and site of contact ulcers. 
CHAPTER IV

RESUITS.

I. GENERAL

Twenty-one (78 percent) of the originally identified twenty-seven subjects responded to the research questionnaire. Section one of the questionnaire revealed information pertaining to sex, occupation and change of handedness. Physician identification of subject's age is also included in this discussion.

Research data indicated 18 ( 86 percent) of the respondents were male and 3 (14 percent) were female. Subjects ranged in age from twenty-one years to sixty-six years with an estimated mean age of forty-nine years. The estimated mean age for female respondents was forty-eight years and forty-nine years for the male respondents. Specific occupations reported by the subjects were classified according to the nine categories (See Appendix E) designated by the U.S. Department of Labor in the Dictionary of Occupation Titles: Definitions and Titles, W. Willard Wirtz (ed.), 1965. Classifications are cited in Table I. It will be noted that the additional category of housewife was included in the classification system to facilitate ease of placement. 
TABLE I

JOB CIASSIFICATIONS

\begin{tabular}{|c|c|c|c|}
\hline & Category & Number & Percentage \\
\hline & $\begin{array}{l}\text { Professional, Technical and } \\
\text { Managerial }\end{array}$ & 7 & $33.3 \%$ \\
\hline 2. & Clerical and Sales Occupations & 3 & $14.2 \%$ \\
\hline 3. & Service Occupations & 2 & $9.5 \%$ \\
\hline 4 . & $\begin{array}{l}\text { Farming, Fishery, Forestry and } \\
\text { Related occupations }\end{array}$ & 2 & $9.5 \%$ \\
\hline 5. & Processing Occupations & 0 & 0 \\
\hline 6. & Machine-Trades Occupations & 0 & 0 \\
\hline 7. & Bench Work Occupations & 0 & 0 \\
\hline 8. & Structural Work Occupations & 2 & $9.5 \%$ \\
\hline 9. & Miscellaneous & 4 & $19.1 \%$ \\
\hline 10. & Housewife & 1 & $4.9 \%$ \\
\hline
\end{tabular}

Examination of occupation classification data revealed that the largest category ( 33 percent) of subject's professions fell in the classification of Professional, Technical and Managerial positions. The second largest category (19 percent) was that of Miscellaneous, which included such occupations as truck driver, Iumberman and house painter. The non-represented categories (O percent) were (1) Processing, (2) Machine-Trades and (3) Bench Work. With regard to change of handedness, one subject indicated an attempt was made to change his handedness. 
The subject stated he had never been right-handed but that at about the age of 8 or 9, his teachers had attempted to change his handedness when he was learning to write. When the subject experienced difficulty in this task; he was allowed to continue writing with his left hand.

Section two of the questionnaire revealed data concerning the subject's handedness. The method of scoring used for determining handedness was adapted from the Revised Iowa Hand Usage Test. A DQ served as the means of assigning a percentage score of the total achievement Involved in this test of handedness, which was credited to the right hand. A DQ score falling above .50 indicated a tendency to use the right hand in the performance of the activities tested. A DQ score falling below .50 indicated a preference for the use of the left hand in the designated activities. In this manner the determination of subject's handedness was able to be based upon the $D Q$ scores achieved.

Comparative Analysis

(Experimental and Pilot Study)

To determine the reliability of test items selected for the research questionnaire and those adapted from the Iowa Hand Usage Test, the $D Q$ scores of both the experimental and pilot study were compared. Table II shows the results of the DQ scores computed for both groups on the 15-item research test and on the original 8 items adapted from the Iowa Hand Usage Test. 


\section{TABIE II}

COMPARTSON OF DQ SCORES FOR RESEARCH SAMPIE

(R) $(N=21)$ AND PIIOT STUDY (PS) $(N=21)$ BASED ON 15-ITEM AND 8-ITEM TESTS

\begin{tabular}{|c|c|}
\hline $\begin{array}{l}\text { (R) 15-Item DQ Scores } \\
\text { Percentiles }\end{array}$ & (PS) 15-Item DQ Scores \\
\hline $\begin{array}{ll}1 . & \\
2 \cdot & \\
3 \cdot & .366 \\
4 \cdot & .464^{*}, .466 \\
5 \cdot & .566 \\
6 . & \\
7 \cdot & .700 \\
8 . & .866 \\
9 \cdot & .900, .933, .933, .933, \\
10 . & .933, .933, .933 \\
& 1.00,1.00,1.00,1.00,1.00\end{array}$ & $\begin{array}{l}.133, .166 \\
.333 \\
.733, .766 \\
.866, .866, .866 \\
.933, .933, .933, .933, \\
.933, .966, .966 \\
1.00,1.00,1.00,1.00 \\
1.00,1.00\end{array}$ \\
\hline $\begin{array}{l}\text { (R) 8-Item DQ Scores } \\
\text { Percentiles }\end{array}$ & (PS) 8-Item DQ Scores \\
\hline $\begin{array}{ll}1 . & \\
2 \cdot & \\
3 \cdot & .312, .312 \\
4 \cdot & \\
5 \cdot & .562 \\
6 \cdot & .625 \\
7 \cdot & .785 \\
8 . & .812, .875, .875, .875 \\
& .875 \\
9 . & .937, .937 \\
10 . & 1.00,1.00,1.00,1.00 \\
& 1.00,1.00,1.00,1.00 \\
1.00 & \end{array}$ & $\begin{array}{l}.125, .125 \\
.375 \\
\\
.640 \\
.750 \\
.875, .875, .875, .875 \\
.875 \\
.937, .937, .937, .937 \\
1.00,1.00,1.00,1.00 \\
1.00,1.00,1.00\end{array}$ \\
\hline
\end{tabular}

Employing the Spearman Rank Correlation Coefficient for the experimental group 15-item test and the pilot study 
8-item test, a value of .96 was found to be highly significant at the .005 level of significance. A value of .95 was obtained for the experimental group 8-item test and pilot study 15-item test which was determined to be highly significant at the .005 level of significance. Thus, it may be concluded that the research test constructed for this study, due to its high degree of correlation with the original items selected from the Iowa Hand Usage Test, appears to be a reliable measure of handedness. Two subjects, within the experimental group, indicated by asterisks (*), failed to answer one question each on the assigned 15-item task. One subject did not answer question number six (crease paper) and the other subject failed to respond to question twelve (brush hair) due to the inappropriateness of the question. The subject indicated that he no longer had any hair and therefore could not respond. In the case of these two subjects it was necessary to pro-rate their scores on the basis of a 14item test.

It is interesting to note that an attempted change of handedness for one subject in the research sample $(D Q=.366)$ did not appear to change significantly hand preference from the left to the right on the selected test items. It will be further noted that this subject's $D Q$ score for percentage of activities performed by the right hand is the lowest score that occurred in the experimental 
sample.

Figures 2-5 graphically represent obtained DQ scores. The distributions appear to be unimodal and are skewed toward the right which represents right handedness tendencies. Estimated mean for the experimental sample based on the 15-item research test is .85, while the estimated mean for the pilot study is .83. Estimated mean for the original 8-item test is .85 for the experimental sample and .80 for the pilot study.

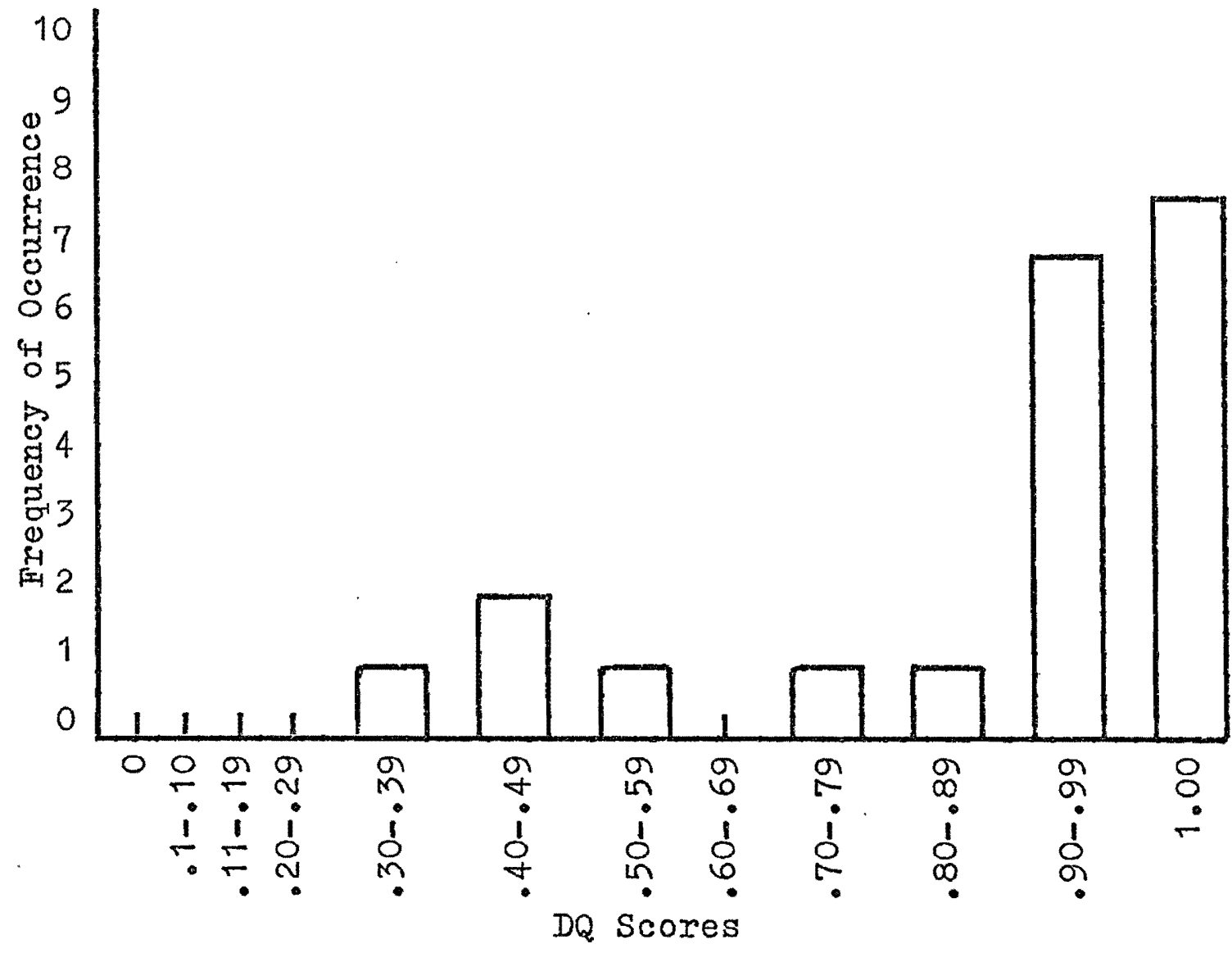

Figure 2. Frequency of occurrence and distribution of DQ scores based on 15-item test for 21 experimental subjects. 


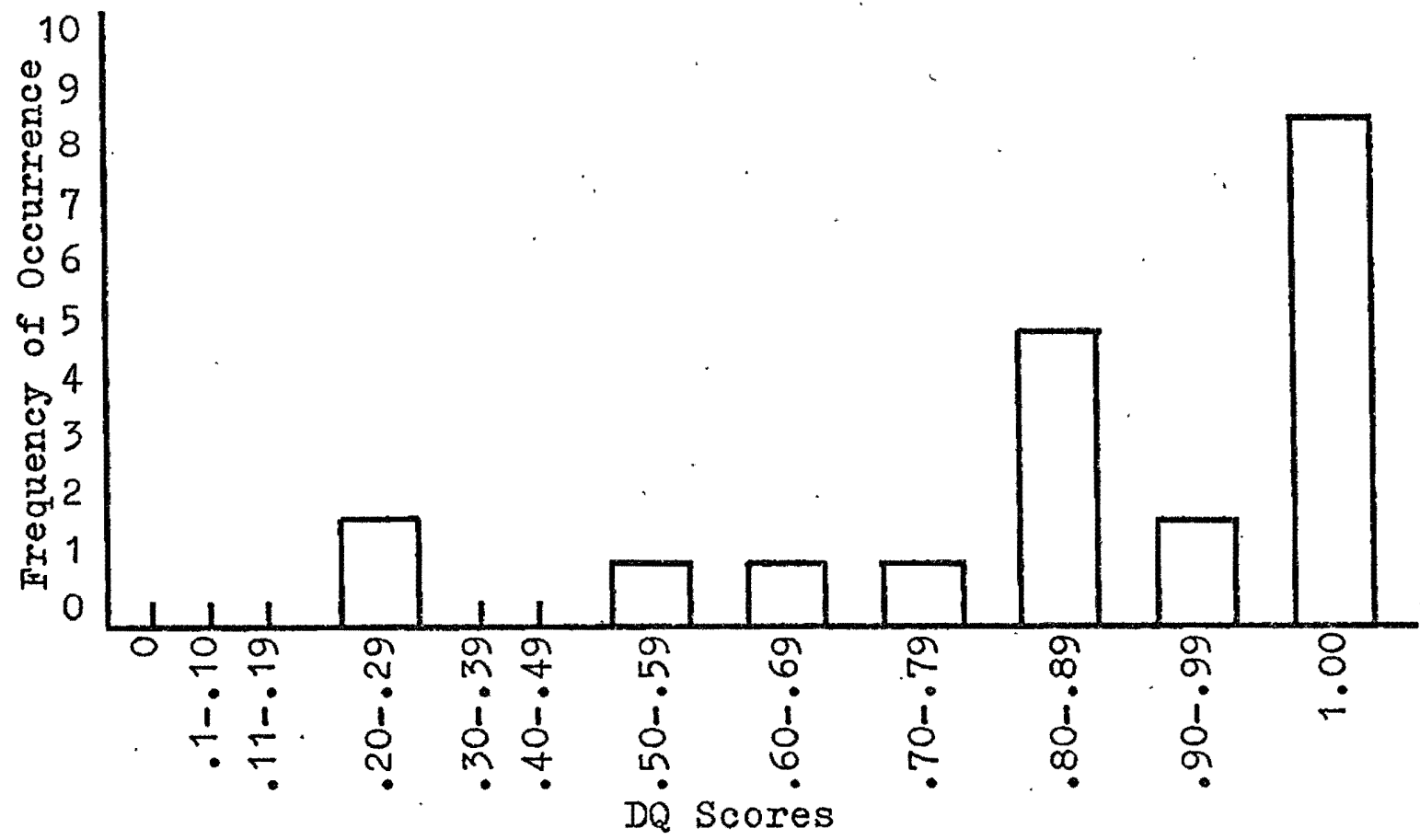

Figure 3. Frequency of occurrence and distribution of $D Q$ scores based on 8-item test for 21 experimental subjects.

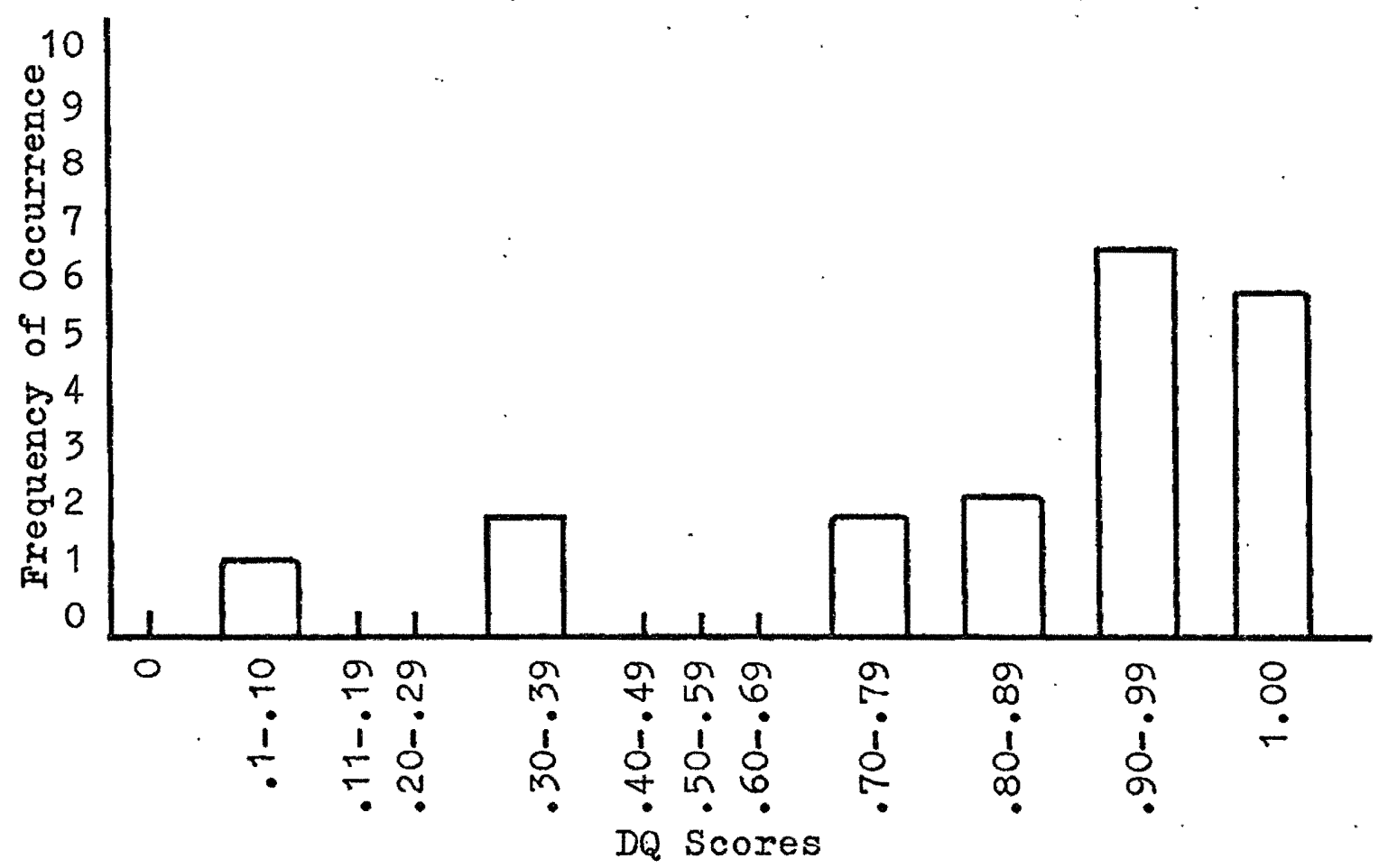

Figure 4. Frequency of occurrence and distribution of DQ scores based on 15 -item test for pilot study. 


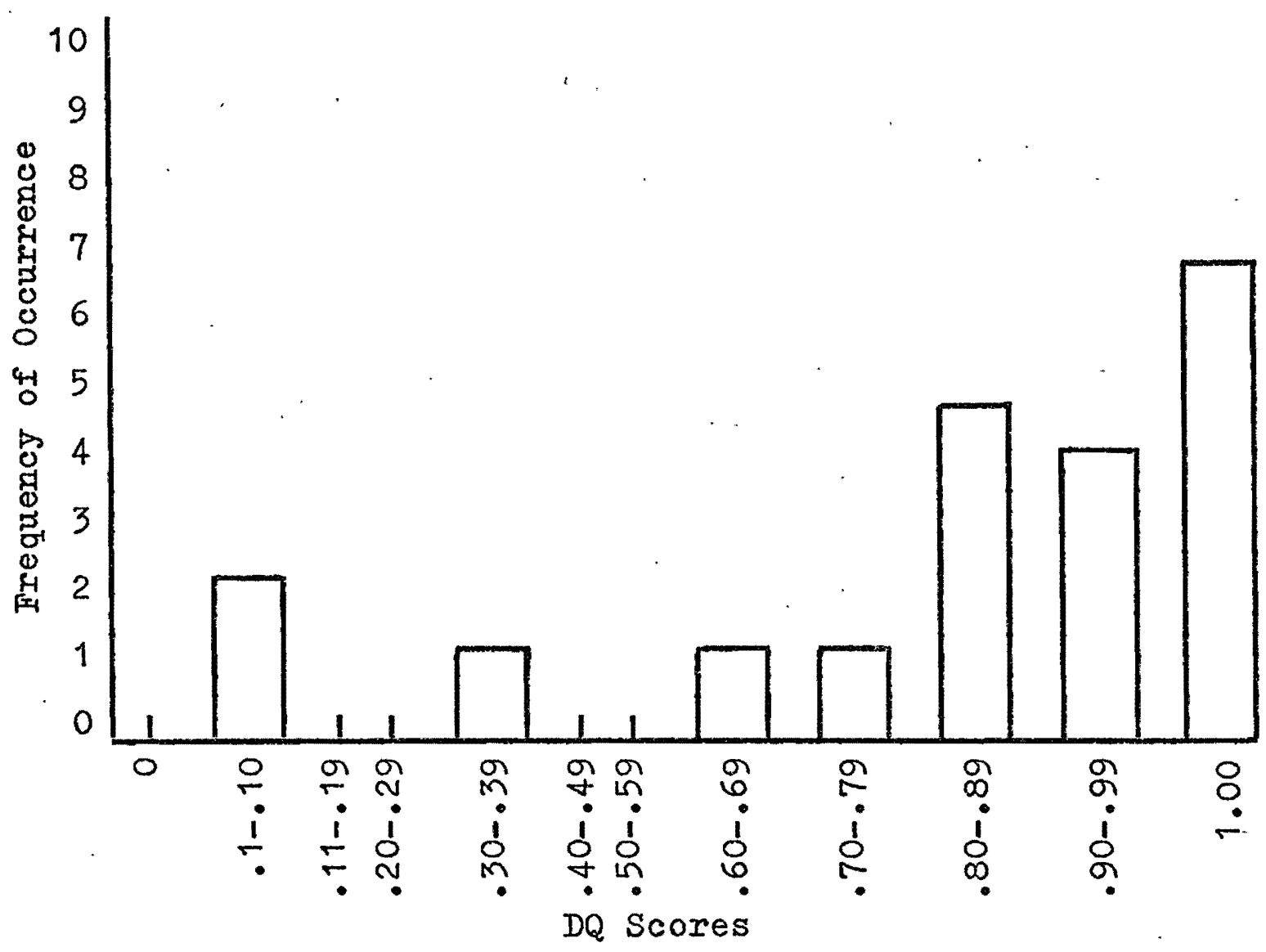

Figure 5. Frequency of occurrence and distribution of DQ scores based on 8-item test for pilot study.

\section{Identification of the Site of Ulcer}

Determination of the site of contact ulcers was estab- .

lished by physician identification. When bilateral ulcers occurred, the larger ulcer was designated. In the case of one subject with bilateral lesions the ulcers were determined to be the same size, therefore, no comparison with this subject's handedness could be made. The research population thus was reduced to 20 subjects. Table III shows the frequency of occurrence of the contact ulcer on the right or left rocal processes with the corresponding 
right or left handedness.

TABLE III

SITE OF ULCER AND DERERMINED HANDEDNESS

FOR RESEARCH $(R)$ SAMPIE $(\mathrm{N}=20)$

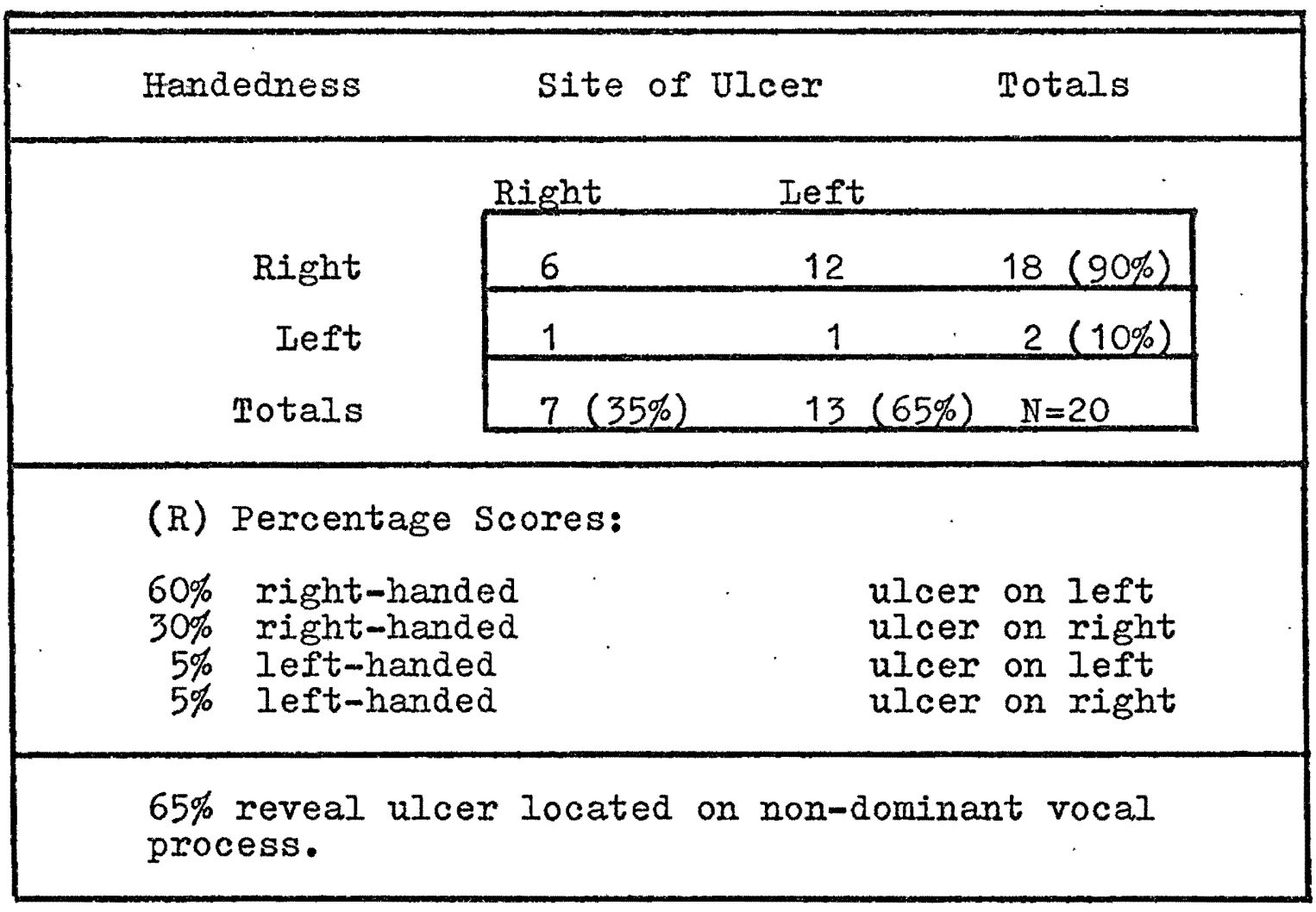

For purposes of comparative analysis, the original findings of the Peacher (1961) study of handedness and site of contact ulcers, are included in Table IV. To facilitate the discussion and identification of the research sample data $(R)$, and the Peacher sample (P) data, the letters $(R)$ and $(P)$ will be used.

Examination of Tables III and IV indicates that 90 percent (18) of the research subjects were right-handed 
TABIE IV

SITE OF ULCER AND DETERMTNED HANDEDNESS PEACHER ( $P$ ) 1961 SAMPIE

(P) Percentage Scores:

$81 \%$ right-handed

$12 \%$ right-handed

$2 \%$ left-handed

$5 \%$ left-handed ulcer on left

ulcer on right

ulcer on right

ulcer on left

$83 \%$ reveal ulcer located on non-dominant vocal process.

and 10 percent (2) were left-handed. Peacher cites 93 percent right-handed and 7 percent left-handed. Thirtyfive percent $(N=7)$ of the research subjects possessed the contact ulcer on the right vocal process, while 65 percent $(N=13)$ possessed the lesion on the left vocal process. Peacher cites 86 percent possessing the ulcer on the left vocal process while 14 percent had right-sided ulcers. The contact ulcer occurs 83 percent of the time on the non-dominant rocal process in the Peacher sample and 65 percent of the time for the research sample.

The percentages computed for the occurrence of the site of the lesion and subject's handedness indicate the majoxity of right-handed subjects possessed the lesion on the left vocal process ( $R=60$ percent, $P=81$ percent). For left-handed subjects the Peacher study indicates the majority of subjects possessed the lesion on the left 
vocal process while the research study shows that the ulcex occurred equally ( 5 percent on right side and 5 percent on the left side) on both rocal processes. The significance of the percentage difference between right-handed subjects with right-sided ulcers ( $P=12$ percent, $R=30$ percent) cannot adequately be determined since the size of the Peacher sample is not given.

II. SPECIFIC HYPOTHESES

Two hypotheses were stated in the form of the null hypothesis in Chapter I.

Hypothesis (I): The proportion of right-handed subjects with left-sided ulcers is equal to the proportion of left-handed subjects with left-sided ulcers.

Based on the application of the Test of the Difference Between Two Proportions a $Z$ value of .47 was not found to be significant and therefore it was concluded that for the present the proportion of right-handed people with leftsided ulcers equals the proportion of left-handed people with left-sided ulcers. Hypothesis one therefore was not rejected.

Hypothesis (II): The proportion of right-handed subjects with right-sided ulcers is equal to the 
proportion of left-handed subjects with right-sided ulcers.

Based on the application of the Test of the Difference Between Two Proportions a $\underline{Z}$ value of -.47 was not found to be significant and therefore it was concluded that for the present the proportion of right-handed subjects with right-sided ulcers equals the proportion of left-handed subjects with right-sided ulcers. Hypothesis two therefore was not rejected.

In order to measure the degree of association between the two research variables, (site of ulcer and handedness), the Phi Coefficient was computed. The degree of association between the two vaxiables as tested by the Phi Coefficient was .098 which was not significant. Hence, it was concluded that site of the lesion and handedness occurs randomly or if one variable is given it is not possible, given that knowledge, to predict the outcome of the other variable. 


\section{CHAPTER V}

\section{DISCUSSION}

The primary purpose of this study was to investigate the relatjonship of the site of contact ulcers and subject's handedness. Results reported in the preceding chapter suggest that the site of contact ulcers is not related to subject's handedness. More specifically no significant differences could be determined to support the theory that the contact ulcer occurred more frequently on the non-dominant vocal process in right or left-handed subjects. Thus, the first and second null hypotheses of this study are supported by these results. This finding is contrary to those of other investigators who found relationships between subject's handedness and the site of contact ulcers (Wolcott, 1956; Peacher 1961).

Such disparity in results might be explained on the basis of the contact ulcer sample and on the basis of the research handedness test.

First, the contact ulcer subjects sampled in this study $(N=21)$ and the left-handed population studied $(N=2)$ were small. With a greater number of subjects and more specifically left-handed subjects, the occurrence of right or left-sided contact ulcers may not have been so randomly 
distributed. Also the results of this study reveal that in the left-handed population there is no tendency for the ulcer to occur more frequently on either the right or left rocal process. In contrast to this result Peacher's (1961) investigation found that 5 percent of her subjects who were left-handed possessed the ulcer on the left vocal process and 2 percent possessed the lesion on the right vocal process. As previously cited, the Peacher findings for the left-handed population do not support a dominance theory. Additionally, the significance of the Peacher data are difficult to determine since the number of subjects studied is not specifically given. The Wolcott study of 1956, based on 5 subjects, supports a dominance theory, however, his research population, due to its small size (4 right-handed subjects, 1 left-handed subject) may not be representative.

A second plausible explanation for the lack of relationship between handedness and site of contact ulcers found in this study may lie in the handedness test constructed for this investigation. Previous studies (Wolcott, 1956; Peacher, 1961) hypothesizing that right and lefthandedness is related to the occurrence of contact ulcer on the right or left vocal process, fail to cite the method used to establish subject's handedness. The present investigation by virtue of its cited method of determining handedness allows the study to be replicated by future researchers. In contrast the percentages given by Peacher 
(1961) are difficult to apply to replicated data due to the lack of information cited.

Finally, it is plausible that the contact ulcer subjects in this study would demonstrate different handedness tendencies on a more discriminative test or battery of tests and therefore reveal a significant relationship between handedness and site of contact ulcers and make possible the prediction of ulcer location given the knowledge of subject's handedness.

To summarize, the writer has suggested possible reasons for the finding that no significant relationship appears to exist between site of contact ulcers and subjeet's handedness. It was suggested that a larger research sample and in particular, a larger left-handed population, might elicit a significant relationship between the location of contact ulcers and subject's handedness.

The handedness test itself might be responsible in part for the absence of significant relationship between ulcer location and handedness in this study. It has been suggested that the use of a more discriminative test, or battery of tests might result in establishing a definite association between the site of the lesion and handedness.

Although further experimentation based on such speculation is necessary, results of this study suggest that the site of contact ulcers is not related to subject's handedness and no evidence is apparent that the prediction of 
ulcer location is possible when the subject's handedness is known.

It has also been noted that there is a trend in the literature to 1) discuss the occurrence of contact ulcers as a hammer and anvil condition set up by the arytenoids inappropriately coming in contact with each other, and 2) that due to muscle imbalance, which may be related to dominance, one arytenoid serves as the "hammer" resulting in the non-dominant "anvil" becoming ulcerated. Superficially, acceptance of such hypotheses would present a plausible explanation for occurrence of the site of the lesion on the right or left vocal process. These hypotheses, however, break down at the point subject's handedness (dominance) is related to the site of the occurring lesions. Since the majority of people are right-handed, the ulcer would be expected to occur more frequently on the left vocal process. Brodnitz (1961), although he presented no data, challenged the hammer and anvil theory for ulcer occurrence following the inspection of several series of investigations.

The data of this study supports Brodnitz's claim and is counter to the above stated hypotheses as well as the interpretations of Wolcott (1956) and Peacher (1961).

The present study would seem to suggest that the previous conclusions found broady in the literature (Wolcott, 1956; von'Leden and Moore, 1960; Peacher, 1961; 
and Iuchsinger and Arnold, 1967) should be further investigated using much larger samples or stated in future texts with greater caution as to the validity of such a theory.

A secondary question related to the purpose of this study involved the possible relationship of the factors of age, sex and occupation of the sample studied. Results indicated 86 percent of the sample were male and 14 percent were female. This finding supports those of previous studies (Jackson, 1933; Peacher, 1947; New and Devine, 1949; Holinger and Johnston, 1960; and Brodnitz, 1962) which have reported that a contact ulcer is primarily a pathology of the male.

The mean age for subjects was found to be fortynine years which further corroborates studies reporting the occurrence of the ulcer in middle-aged subjects (Peacher, 1947; Holinger and Johnston; 1960; and Brodnitz, 1962).

The occupations of the majority of research subjects were found to be those of professional, technical and managerial positions. As has been previously stated, these jobs are most often associated with tension-producing situations and vocal abuse (Jackson, 1933; Peacher, 1947; Moses, 1954; Brodnitz, 1958; Holinger and Johnston, 1960; and Boone, 1967).

On the basis of the results reported, the sample participating in this investigation would appear to be 
representative of contact ulcer patients as indicated by the close agreement with reports of previous studies.

To summarize, the findings of this study would appear to further substantiate the belief that the con- tact ulcer lesion occurs among a predominantly middleage male population, who demonstrate vocal hyperfunction and whose occupation may be associated with vocal stress and strain. 
CHAPTER VI

SUMMARY AND IMPIICATIONS

\section{SUMMARY}

This investigation attempted to determine the relationship of the site of contact ulcers and subject's handedness. Iiterature concerned with contact ulcers has indicated that cerebral dominance tends to determine the site of the lesion. Four research questions were posed, two questions were presented in the form of the null hypothesis. The questions were: (1) Is the proportion of right-handed subjects with left-sided ulcers equal to the proportion of left-handed subjects with left-sided ulcers? (2) Is the proportion of right-handed subjects with right-sided ulcers equal to the proportion of lefthanded subjects with right-sided ulcers? (3) Will the site of contact ulcers be able to be predicted from subject's handedness? and (4) Is there a significant relationship between the factors of age, sex and occupation of the sample studied and the occurrence of contact ulcers?

The research sample was composed of 21 former contact ulcer patients identified by their physicians. Eighteen subjects were male, three were female. Subjects ranged in 
age from twenty-one years to sixty-six years, with a mean age of forty-nine years. Subject's handedness was determined by means of a 15-item questionnaire constructed for this research study. Identification of the site of contact alcers was made by medical records and physician designation. The Test of the Difference Between Two Proportions, the Phi Coefficient and percentages were used in processing the data. The major findings were as follows:

1. The proportion of right-handed subjects with left-sided ulcers is equal to the proportion of left-handed subjects with left-sided ulcers.

2. The proportion of right-handed subjects with right-sided ulcers is equal to the proportion of left-handed subjects with right-sided ulcers.

3. No statistical significance could be determined to support the hypothesis that the site of contact ulcers can be established from subject's handedness.

4. The majority of subjects sampled were middle-age males, employed in professional, technical or managerial positions.

On the basis of the sample of contact ulcer patients studied and the dimensions of location of the lesion and handedness involved in this investigation, the following conclusions appear to be warranted:

1. Handedness is not a determining factor in the 
site of contact ulcers.

2. It is not possible to predict the location of a contact ulcer based on knowledge of subject's handedness.

3. Contact ulcers occur more frequently in middleage males, whose occupations may be associated with vocal stress and strain.

II. IMPIICATIONS FOR FUTURE RESEARCH

It is suggested for future studies of this nature that the population of contact ulcer subjects be larger in number. Due to the small size of the sample studied in this investigation, statistical interpretation of results. was limited. Specifically, future researchers should attempt to gather a representative sample of left-handed subjects. Since the occurrence of contact ulcers is very infrequent, the scarcity would dictate that the future researcher broaden the geographical area and number of specialists contributing to a larger study. This would greatly facilitate comparisons between right and lefthanded subjects and site of occurring contact ulcers.

In the future, it may be of interest to question subjects as to their considered handedness. It is possible that a handedness test imposes Iimitations on the true innate handedness tendencies of the persons being studied based on the bias of the researcher's test items, methods 
and procedures. Comparison of a handedness test score and personal idea of handedness might also prove beneficial. Direct observation of hand usage may be another suggested procedure to aid in accurate determination of subject's hand preference. 


\section{BIBLIOGRAPHY}

Arnold, G. E., Vocal Nodules and Polyps: Laryngeal Tissue Reaction to Habitual Hyper Kinetic Dysphonia. J. Speech Hearing Dis., 27, 205-217 (1962).

Baker, D. C., Contact Ulcer of the Larynx. Laryngoscope, 64, 73-78 (1954).

Benton, A. I., Right-left discrimination and finger localjzation; development and Pathology. New York: Hoeber-Harper (1959).

Blau, A., The Master Hand. N.Y.: Amer. Orthopsychiatric Assoc. (1946).

Boone, D., The Voice and Voice Therapy Englewood Cliffs, New Jersey: Prentice-Hall Inc. (1971).

Brodnitz, F. S., Vocal Rehabilitation in Benign Lesions of the Vocal Cords. J. Speech Hearing Dis., 23, $112-117$ (1958).

, Vocal Rehabilitation. Rochester, Minnesota: Whiting Press (1959).

- Contact Ulcer of the Larynx. Archives of Otolaryngology, 74, 70-80 (1961).

Bruning, J. I., and Kintz, B. I., Computational Handbook and Statistics. Glenview, Illinois: Scott, Foresman and Co. (1968).

Buck, M., Dysphasia. Englewood Cliffs, New Jersey: Prentice-HalI (1968).

Corballis, M. C., and Beale, T., Bilateral Symmetry and Behavior. Psychol. Rev., 77, 451-464 (1970).

Deweese, D., and Saunders, W., Textbook of Otolaryngology. St. Louis: C. V. Mosby Co. (1964).

Dorland's Illustrated Medical Dictionary. 23rd ed. Philadelphia: The W. B. Saunders Co. (1957). 
Ferguson, G. B., Organic Iesions of the Larynx Produced by Mis-Use of the Voice. Laryngoscope, 65, 327-337(1955).

Harris, A., Harris Tests of Lateral Dominance. New York: Psychological Corporation (1958).

Hecaen, H., and Ajuriaguerra, J., Ieft-Handedness, Manual Superioxity and Cerebral Dominance. New York: Grune \& Stratton (1964).

Holinger, P. H., and Johnston, K. C., Contact Ulcer of the Iarynx. J.Amer. Med. Assoc., 1122, 511-515 (1960).

Hurlock, E'. B., Developmental Psychology. N.Y.: McGrawHill (1959)。

Jackson, C., Contact Ulcer of the Iarynx. Annals of otology, Rhinology and Laryngology, 37, 227-30 (1928).

- Etiology and Treatment of Contact Ulcer. Laryngoscope, 43, 718-721 (1933).

- Diseases and Injuries of the Larynz. New York: The Mac Millian Co. (1942).

Johnson, W., and Duke, D., The Dextrality Quotients of Fifty Six-Year Olds With Regard to Hand Usage. J. Educ. Psychol., 27, 26-36 (1936).

, and Davis, D., Dextrality Quotients of SevenYear olds in Terms of Hand Usage. J. Educ. Psychol, $28,346-354$ (1937).

- and Duke, D., Revised Iowa Hand Usage Dextrality Quotients of Six-Year Olds. J. Educ. Psychol., 31 , $45-52(1940)$.

, and Bissell, V., Iowa Hand Usage Dextrality Quotients of One Hundred High School Students. J. Educ. Psychol., 31, 148-152 (1940).

Iuchsinger, R., and Arnold, G. E., Voice-Speech-Ianguage. Belmont, Calif.: Wadsworth Publishing Co. (1967).

Moses, P., The Voice of Neurosis. New York: Grune and Stratton Inc. (1954).

New, G. B., and Devine, K. D., Contact Ulcer Granuloma. Annals of Otology, Rhinology and Laryngology, 58, $548-558(1949)$. 
Orton, S. T., Reading, writing and speech problems in children. New York: W. W. Norton \& Co. (1937).

Peacher, G., Contact Ulcer of the Larynx IV. A Clinical Study of Vocal Rehabilitation. J. Speech Dis., 12, 179-190 (1947).

, Vocal Therapy for Contact Ulcer of the Iarynx. A Follow-up of 70 patients. Laryngoscope, 71, 37$47(1961)$.

Rubenstein, C. R., Contact Ulcer of the Larynx. Califormia Medicine, 86, 275-276 (1957).

Selzer, C. A., Iateral Dominance and Visual Fusion. Cambridge: Harvard University Press (1933).

Taber, C. W., Tabex's Cyclopedic Medical Dictionary. Philadelphia: F. A. Davis Co. (1970).

Van Riper, C., and Irwin, J. V., Voice and Articulation. New Jersey: Prentice-Hali (1958).

von Leden, H., and Moore, P., Contact Ulcer of the Iarynx: Experimental 0bservations. Archives of otolaryngology, 72, 746-752 (1960).

Walpole, R. E., Introduction to Statistics. New York: Mac Millian Co. (1968).

Webster's Seventh New Collegiate Dictionary. Springfield, Mass.: G. and C. Merriam Co. (1965).

Wile, I. S., Handedness, Right and Left. Boston: Lothrop, Lee and Shephard (1934).

Wolcott, C., Contact Ulcer of the Larynx. Annals of otology, 65, 816-819 (1956). 
APPENDIX A

FORM LETTER SENT TO PHYSICIANS 


\section{Dear Doctor:}

I am a Graduate Student at Portland State University, majoring in Speech Pathology and Audiology. Currently, I am engaged in a funded research project concerning the relationship, if any, of the site of contact ulcer lesions and the patient's handedness. Principal investigator and thesis director in this general area of research is Robert I. Casteel, Ph.D., Coordinator of Training and Services in Speech Pathology, Department of Speech, Portland State University.

The aim of my research is to investigate the hypothesis that a contact ulcer will appear predominantly on the left vocal process regardless of handedness.

Interest for this research was generated by an article authored by Dr. Georgiana Peacher (Iaryngoscope, 71:37-47, 1961), in which she hypothesized that Cerebral Dominance was related to the site of contact ulcers. She found right and left handedness was related to the site of the ulcer on the right or left vocal cord. She also found the ulcer to be present on the non-dominant vocal cord in 83 percent of her subjects. Several discrepancies, however, were noted in this study; they are (1) the size of the sample used is not specifically stated; (2) the method of determining handedness is not presented; (3) sex incidence is not noted and (4) Dr. Peacher's conclusion is not substantiated in the left handed population (where 5 percent possessed the ulcer on the left side and 2 percent possessed the ulcer on the right side).

In order to test the hypothesis I am asking for your assistance in obtaining subjects for my study. These subjects will not be confronted personally, rather information will be obtained through a questionnaire for the purpose of collecting data with regard to their handedness. As per clinical practice, confidentiality will be observed. Subjects will not be required to sign their names to the questionnaire. To eliminate duplication of subjects, I am requesting your cooperation in obtaining the names of contact ulcer patients and the site of their lesion, i.e. right, left or bilateral. If you are willing to cooperate in this research project, I will contact you relative to the method of releasing the names.

Your cooperation in furthering this research will be 
greatiy appreciated and may cause revisions of previous literature and/or further substantiate the hypothesis that handedness is related to the site of contact ulcers.

If you have any questions concerning this research, please call either Dr. Robert I. Casteel at 229-3534 or Miss Colleen Colleary at 229-3533 or 636-7443.

Sincerely yours,

Colleen S. Colleary

Robert I. Casteel, Ph.D. 


\section{APPENDIX B}

\section{STAMPED, SEIF-ADDRESSED POST CARD}

SENT TO PHYSICIANS 
If you have patients with a history of contact ulcers, to whom we might send the research questionnaire, please return this card.

Yes 
APPENDIX $\mathrm{C}$

QUESTIONNAIRE ON SUBJECT'S OCCUPATION, SEX, AND HANDEDNESS 
QUESTIONNAIRE

Please place your occupation on the following line

Maie_ Female

Have you ever been changed from right to left handed?

Yes_ No

If the answer to the above question is yes at what age?

Have you ever been changed from left to right handed?

Yes__ No

If the answer is yes at what age?

If the answer is yes to either of the above questions what was the reason for the change?

Please place a check mark ( ) in the appropriate spaces below to indicate whether the activities listed are performed by the right hand $(R)$, the left hand (L), or both hands $(B)$, neither hand predominating. If you are uncertain about which hand performs some activity, practice the task 2 or 3 times and mark the appropriate space.

Which hand do you normally use to: $\mathrm{R} \quad \mathrm{I} \quad \mathrm{B}$

1. Write with a pen

2. Draw a picture

3. Pick up scissors

4. Point to an object

5. Turn a page in a book

6. Crease paper

7. Throw a ball

8. Eat with a spoon

9. Turm a dial 
R I $\quad$ B

10. Cut paper

11. Erase with a pencil

12. Brush hair

13. Brush teeth

14. Turn a door $\mathrm{knob}$

15. Snap your fingers

三三三三三

THANK YOU FOR COMPLETING THIS QUESTIONNAIRE 
APPENDIX D

INTRODUCTORY LEPTER SENT TO PATIENTS 
Dear Mr.

At the present time $I$ am engaged in a funded research project concerning contact ulcers.

I learned of your case from your physician, who released your name to me. Your cooperation in participating in this project will greatly aid in achieving a better understanding of the type of voice problem you have experienced.

Your task is a simple one. The enclosed questionnaire can be completed in five minutes, and it is critical to this project that the questionnaire be completely filled out and returned at the earliest possible date. If this research is to be of any value, 100 percent response is needed. Each person's response insures the success of this project. As per clinical practice, confidentiality will be strictly observed. You are not required to sign your name to the questionnaire. A self-addressed, stamped envelope is enclosed for your convenience.

Your assistance in filling out the enclosed questionnaire will not only enable this research to be completed but will be deeply appreciated.

If you have any questions concerning this questionnaire, please call either Dr. Robert I. Casteel at 229-3534 or Miss Colleen Colleary at 229-3533 or 636-7443.

\section{Sincerely,}

Colleen Colleary

Department of Speech

Speech and Hearing Sciences

Box 751

Portland State University

Portland, Oregon 97207 
APPENDIX E

IIST OF SUBJECT'S OCCUPATIONS 


\section{IIST OF SUBJECT'S OCCUPATIONS}

CATEGORY I: PROFESSIONAI, TECHNICAI, AND MANAGERIAI

Job Tit]e Provided by Subject

Number Percentage

Driver's Ed. Instructor

Physician

clergyman (2)

Customer Relations Manager

Sp. Pathologist

Nurse

$7 \quad 33.3 \%$

CATEGORY II: CIERTCAI AND SALES OCCUPATIONS

Salesman

Plywood Salesman

Electrical Appliance Salesman

$3 \quad 14.2 \%$

CATEGORY III: SERVICE OCCUPATIONS

Rate Engineer--Public Utility

Restaurant Owner

$2 \quad 9.5 \%$

CATEGORY IV: FARMTNG, FISHERY, FORESTRY AND RELATED OCCUPATIONS

Farmer

Dairy Farmer

$2 \quad 9.5 \%$

CATEGORY V: PROCESSING OCCUPATIONS

0

0

CATEGORY VI: MACHINE-TRADES OCCUPATIONS 
CATEGORY VII: BENCH WORK OCCUPATIONS

Job Title Provided by Subject

Number Percentage

0

0

CATEGORY VIII: STRUCTURAI WORK OCCUPATIONS

Carpenter (2)

$2 \quad 9.5 \%$

CATEGORY IX: MISCELIANEOUS

Tmuck Driver (2)

Lumberman

House Painter

$4 \quad 19.1 \%$

CATEGORY X: HOUSEWIFE

Housewife

1

$4.9 \%$ 